\title{
Influence of grinding and shot-peening on the near-surface microstructure of a maraging stainless steel
}

\author{
Charline Le Nué ${ }^{\mathrm{a}, \mathrm{b}}$, Alexis Deschamps ${ }^{\mathrm{a}, *}$, Frédéric Danoix $^{\mathrm{c}}$, Frédéric De Geuser ${ }^{\mathrm{a}}$, Gilles Renou ${ }^{\mathrm{a}}$, \\ Marc Verdier $^{\mathrm{a}}$, Thomas Billot ${ }^{\mathrm{d}}$, Nicolas Binot ${ }^{\mathrm{d}}$, Corentin Dides ${ }^{\mathrm{b}}$ \\ a Univ. Grenoble Alpes, CNRS, Grenoble INP, SIMAP, F-38000 Grenoble, France \\ ${ }^{\mathrm{b}}$ IRT M2P, 4 Rue Augustin Fresnel, F-57000 Metz, France

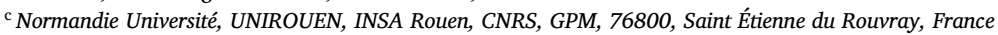 \\ ${ }^{\mathrm{d}}$ Safran Landing Systems, Materials \& Processes Laboratory, BP 39, 64401 Oloron-Sainte-Marie CEDEX, France
}

\section{A R T I C L E I N F O}

\section{Keywords:}

Maraging stainless steel

Machining

Shot Peening

ACOM-TEM

\begin{abstract}
A B S T R A C T
The near-surface properties of maraging steels are key to controlling their mechanical properties. They can be tailored by surface treatments such as shot peening and can also be influenced by prior machining. This study aims at determining the respective roles of grinding and shot peening processes on the near-surface microstructure of Custom 465 maraging stainless steel. A combination of experimental techniques, including X-ray diffraction (XRD), transmission electron microscopy (TEM), and atom probe tomography (APT) provides an in-depth characterization of the initial microstructure and its modifications. The results show that grinding results in a very shallow nano-crystalline region less than $1 \mu \mathrm{m}$ thick, which contains a high fraction of retained austenite and where most $\mathrm{Ni}_{3} \mathrm{Ti}$ precipitates initially present, have been dissolved. Shot peening, on the other hand, results in a moderate localized strain close to the surface, and in a deeper destabilization of the retained austenite initially present, which decreases from $\sim 5 \%$ to $\sim 2 \%$ in the first $100 \mu$ m below the surface. It has no visible effect on the precipitate microstructures. The different mechanisms that may cause these modifications are discussed.
\end{abstract}

\section{Introduction}

Maraging stainless steels offer a promising alternative for replacing conventional high strength martensitic steels for applications requiring high levels of mechanical properties, with a property portfolio comprising high strength, toughness and corrosion resistance [1,2]. However, their fatigue strength, which is an important property for these structural components, is relatively low in comparison with the conventional high strength steels [3]. Shot peening is an effective treatment for improving the fatigue strength of maraging steels [4-7]. This treatment is a cold-work surface treatment that results in the introduction of compressive residual stresses at and immediately beneath the surface, with the purpose of delaying the initiation of surface cracks and pushing the crack initiation to subsurface regions $[8,9]$.

Numerous studies have been performed to improve the state of knowledge on shot peening and gain a better understanding of its effects on surface roughness $[10,11]$ and on the distribution of residual stresses $[8,12,13]$. An extended summary about these changes has been provided by Schulze [14], and by Llaneza and Belzunce [15] on the AISI 4340 steel. However, only a few studies have been carried out on the microstructure changes induced by shot peening, due to difficulties in char- acterizing fine-scale changes in a shallow surface layer (around $1 \mu \mathrm{m}$ ). As reported in the literature, shot peening may result in locally severe plastic deformation and grain refinement, and can lead to a decrease of retained austenite content, as a result of strain-induced transformation. It should be noted that the presence of a nano-crystalline grain structure close to the surface is generally obtained from severe shot peening [16], such as high-energy shot peening [17,18], air blast shot peening $[19,20]$ and ultrasonic shot peening, sometimes entitled surface mechanical attrition treatment [21-23]. Conventional shot peening does not necessarily result in grain refinement in the near-surface layer if the quantity of plastic strain is not sufficient, as reported by Maleki and Unal [24] for the AISI 1045 steel. On the other hand, phase changes due to shot peening are well established, especially for case hardened steel [25,26], duplex steels [27], austenitic steels [28,29] and for maraging steel [30].

The initial near-surface microstructure prior to shot peening is also an important point to analyse and control. Industrial components are generally machined before shot peening, which can result in a significant modification of the surface layer, due to mechanical and thermal effects. The near-surface of machined components, also named white layer, has received some attention in the past decades. Several authors have shown that this white layer is composed of very fine grains

\footnotetext{
* Corresponding author.

E-mail address: alexis.deschamps@grenoble-inp.fr (A. Deschamps).
} 
Table 1

Nominal chemical composition of C465 (mass \%).

\begin{tabular}{lllllll}
\hline $\mathrm{Fe}$ & $\mathrm{C}$ & $\mathrm{Ni}$ & $\mathrm{Cr}$ & $\mathrm{Mo}$ & $\mathrm{Ti}$ & $\mathrm{Si}$ \\
\hline Bal. & 0.01 & 11.1 & 11.5 & 0.9 & 1.7 & 0.05 \\
\hline
\end{tabular}

(size $<100 \mathrm{~nm}$ ) induced by severe plastic deformation during turning or grinding [31-36]. Additionally, except for a few investigators [32,36], various studies have noticed an increase of austenite content in this layer [31,35,37-39] .

The present study is carried out on the Custom 465 maraging stainless steel, which as the other grades of Ti-containing maraging steels, is hardened by the nano meter-scale precipitates of hexagonal $\eta-\mathrm{Ni}_{3} \mathrm{Ti}$ phase [40-46] formed in a martensitic structure. Based on an in-depth analysis of the initial microstructure, the main objective of this work is to evaluate the different near-surface modifications of the microstructure caused by the combination of machining and shot peening, and to understand the respective roles of these two processes on the final microstructure. For this purpose, a systematic characterization is carried out, combining advanced phase and crystal orientation mapping (ASTAR-ACOM $[47,48]$ ) in the transmission electron microscope (TEM) with phase fraction quantification by X-ray diffraction (XRD) and more conventional electron back-scattered electron diffraction (EBSD) in the scanning electron microscope (SEM), as well as atom probe tomography (APT). The microstructure of the base material will be compared to the sub-surface microstructure of components subjected to machining, shot peening and the combination of the two.

\section{Experimental Procedures}

\section{Material}

The steel grade investigated is the commercial Custom $465 \AA$ merging stainless steel (C465). The material was produced using a vacuum induction melting-vacuum arc remelting (VIM-VAR) process. Afterwards, the material was homogenized and forged into a billet of $88.9 \mathrm{~mm}$ in diameter. The chemical composition of the steel investigated is given in Table 1.

The billet was initially solution annealed at $980^{\circ} \mathrm{C}$ for $1 \mathrm{~h}$ followed by water quenching and then refrigerated at $-73^{\circ} \mathrm{C}$ for $8 \mathrm{~h}$ to allow for a more complete martensitic transformation. This state corresponds to the received material. Samples were extracted from the annealed billet, at mid-radius position, along the forging direction. Ageing was performed at $510^{\circ} \mathrm{C}$ for $4 \mathrm{~h}$. After this age-hardening heat treatment, half of the samples were carefully mirror polished to obtain a surface free of any microstructural modifications, using SiC papers, diamond suspension and Master Met finishing using a Vibro Met vibrating polisher. The other half part was ground. Shot peening treatment was performed on both states using an air blast machine, with the following conditions: S230 shot (diameter of $0.58 \mathrm{~mm}$ and hardness of $58 \mathrm{HRC}$ ), coverage of $150 \%$ and Almen intensity of F25A.

\section{Microstructural characterization}

Characterization of the microstructures has been made by using scanning electron microscopy (SEM), electron backscatter diffraction (EBSD), X-Ray diffraction (XRD), grazing incidence XRD (GIXRD), automated crystallographic orientation mapping (ACOM) tool attached to a transmission electron microscope (TEM), and atom probe tomography (APT).

Samples for SEM analysis were prepared by polishing with a diamond suspension and final polishing with colloidal silica suspension. EBSD technique was applied to map the lath martensitic structure, the location and the morphology of the austenite phase in the martensitic matrix. Measurements were performed using a ZEISS Ultra 55 field emis- sion gun scanning electron microscope equipped with a high-speed CCD camera for pattern recording, and analysed by TSL-OIM software. XRD analysis was carried out to determine the austenite volume fraction. The measurements were performed with a PANalytical X'Pert MPD laboratory diffracto meter using a Co K $\alpha$ radiation source $(1.78896 \AA$ ) to avoid Fe fluorescence and therefore to obtain a larger penetration depth, ensuring that the measurements are representative of the bulk material. The diffraction data were collected over a $2 \theta$ range from $47^{\circ}$ to $115^{\circ}$, scanned with a step width of $0.033^{\circ}$ and a counting time of $2 \mathrm{~s}$ per step. The collected spectra were analysed following the Rietveld method using the FullProf software to determine the volume fraction of austenite. GIXRD was performed on a Rigaku Smartlab five-circle diffractometer, using a $\mathrm{Cu} \mathrm{K} \alpha$ radiation source (1.5418 $\mathrm{A}$ ). The acquisitions were conducted from 40 to $85^{\circ}$, with a step of $0.05^{\circ}, 10 \mathrm{~s}$ by step and an incidence angle of $1.8^{\circ}$ (penetration depth around $65 \mathrm{~nm}$ ). ACOM-TEM, using the ASTAR TEM attachment, provides orientation and phase with the resolution of a scanning TEM [48]. Measurements were performed using a JEOL 2100F FEG-TEM operating at an accelerating voltage of $200 \mathrm{kV}$ and equipped with the "Digistar" precession system from NanoMEGAS SPRL. The precession angle was $0.5^{\circ}$ and the step size for the acquisition was $2 \mathrm{~nm}$. Reference samples for ACOM-TEM from the bulk material were mechanically polished to a thickness of $80 \mu \mathrm{m}$, then disks of $3 \mathrm{~mm}$ were punched from the sample. Finally, these disks were electropolished with a double-jet Struers Tenupol-5, using a polishing solution with $70 \%$ vol of ethanol, $20 \%$ vol. of 2-butoxyethanol and $10 \%$ vol. of perchloric acid at $2^{\circ} \mathrm{C}$. Additionally, cross-section TEM thin foils were prepared by Focused Ion Beam (FIB) on a Helios NanoLab 650 (FEI) to evaluate the near surface modifications. Samples for APT were prepared using two different methods. For bulk material analysis, samples were prepared using the two stage electrolytic polishing process to obtain sharp tips suitable for APT analysis [49]. For near surface analysis, specimens were lifted out from a cross section of the shot pinned materials, and welded on silicon pre-tips in a the Thermo Scientific ${ }^{\mathrm{TM}}$ Helios PFIB DualBeam ${ }^{\mathrm{TM}}$ System with Xe ions. Annular milling was conducted until an apex radius of curvature smaller than $70 \mathrm{~nm}$ was obtained. Analyses were conducted on a CAMECA LEAP $\AA 4000$ HR in voltage mode, at a temperature of $50 \mathrm{~K}$, with a pulse to standing voltage ratio of $20 \%$, a nominal pulse repetition rate of $200 \mathrm{kHz}$ and a detection rate of $0.5 \%$. Data were analysed using IVAS 3.8 software.

\section{Characterization of the base material}

\subsection{Microstructure at grain and phase scale}

The grain distribution of the base metal, namely the aged C465 steel, is shown in Fig. 1. Both the optical microstructure (Fig. 1a), and the EBSD orientation map (Fig. 1b) show the typical morphology of lath marten site. The observations reveal the prior austenite grains subdivided into packets, blocks and laths, in agreement with other observations realized on maraging steels $[50,51]$ or in low-carbon steels $[52,53]$. The average size of prior austenite grains is $30 \mu \mathrm{m}$.

The morphology and the localization of the austenitic phase were characterized by EBSD (Fig. 2a) and TEM-ASTAR (Figs. 2 b-e). These observations show that the austenite is characterized by coarse patchy regions located at the prior austenite grain boundaries and by finer elongated regions at the lath boundaries. From these images, it is difficult to obtain a reliable fraction of austenite because of a heterogeneous distribution of austenite and possibly strain-induced transformation during sample preparation (EBSD). Thus, the volume fraction of austenite was obtained from XRD, performed on a mirror polished sample with the same surface finishing as for EBSD. The pattern, shown in Fig. 3, reveals that the microstructure consists of martensitic and austenitic phases, as expected based on the previous observations. The marten site has a bcc structure, which is consistent with the low carbon content of this steel. The volume fraction of austenite, obtained by Rietveld refinement, is $5.8 \pm 0.2 \%$, which is of the same order of magnitude as the results ob- 

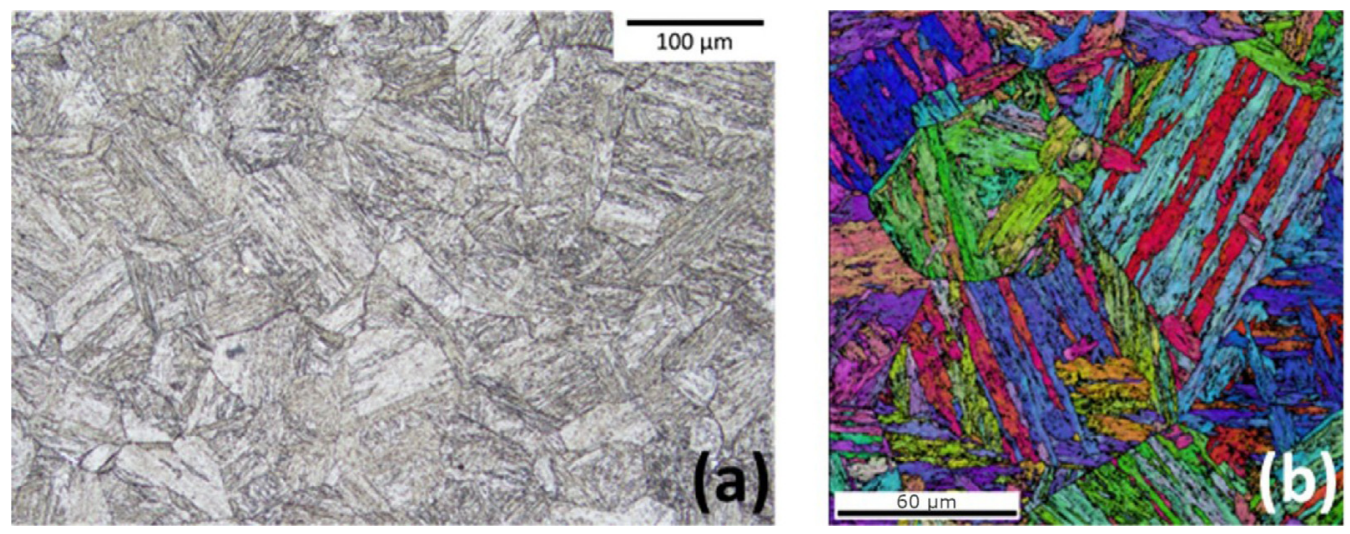

Fig. 1. Optical micrograph of C465 etched at 200X magnification (a) and EBSD-IPF map showing orientation mapping (b).
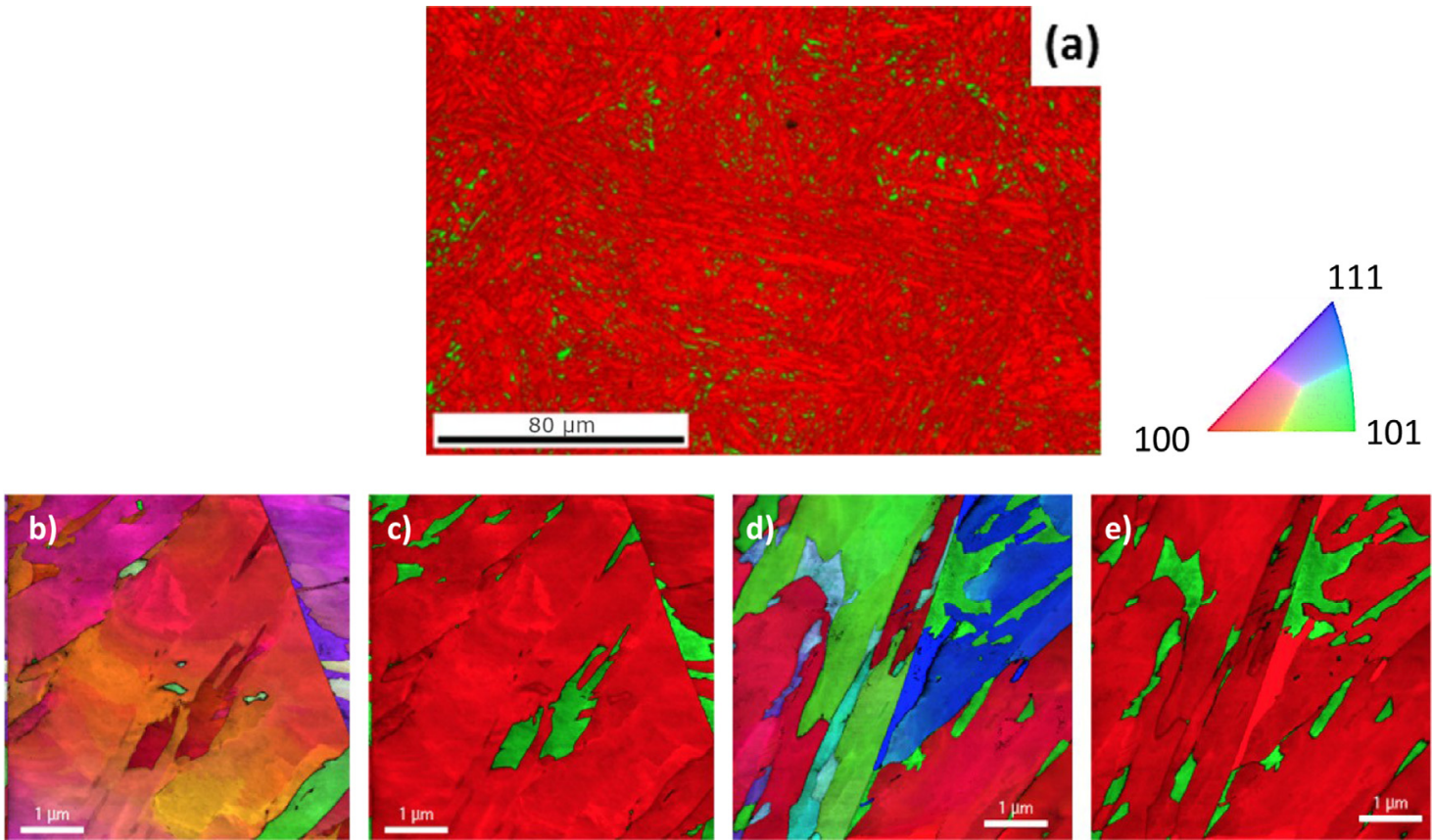

Fig. 2. Phase and orientations map obtained by EBSD (a) and TEM-ACOM/ASTAR (b-e): (a), (c) and (e) distribution of marten site (red) and austenite (green); (b) and (d): inverse pole figures showing orientation mapping

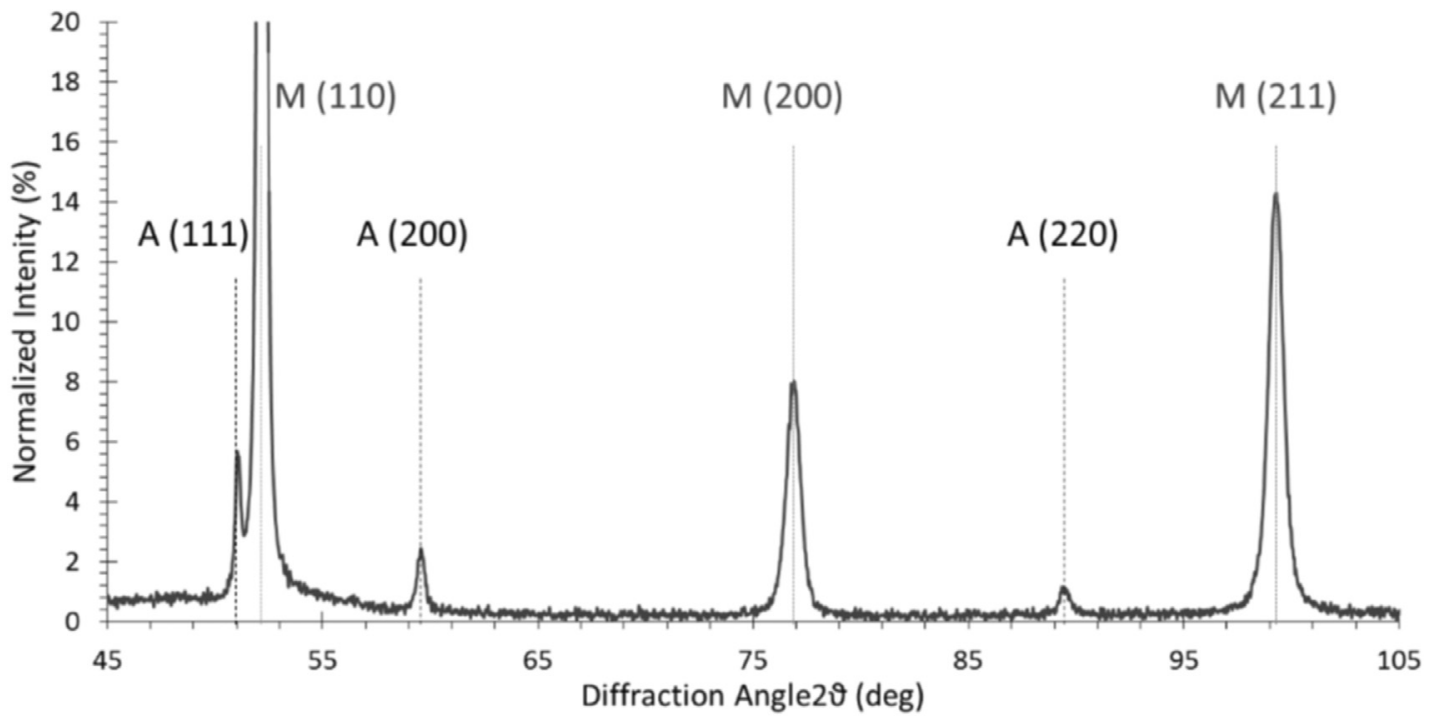

Fig. 3. XRD pattern normalized according to the highest marten site $M(110)$ peak ( $M=$ marten site, $A=$ Austenite). 

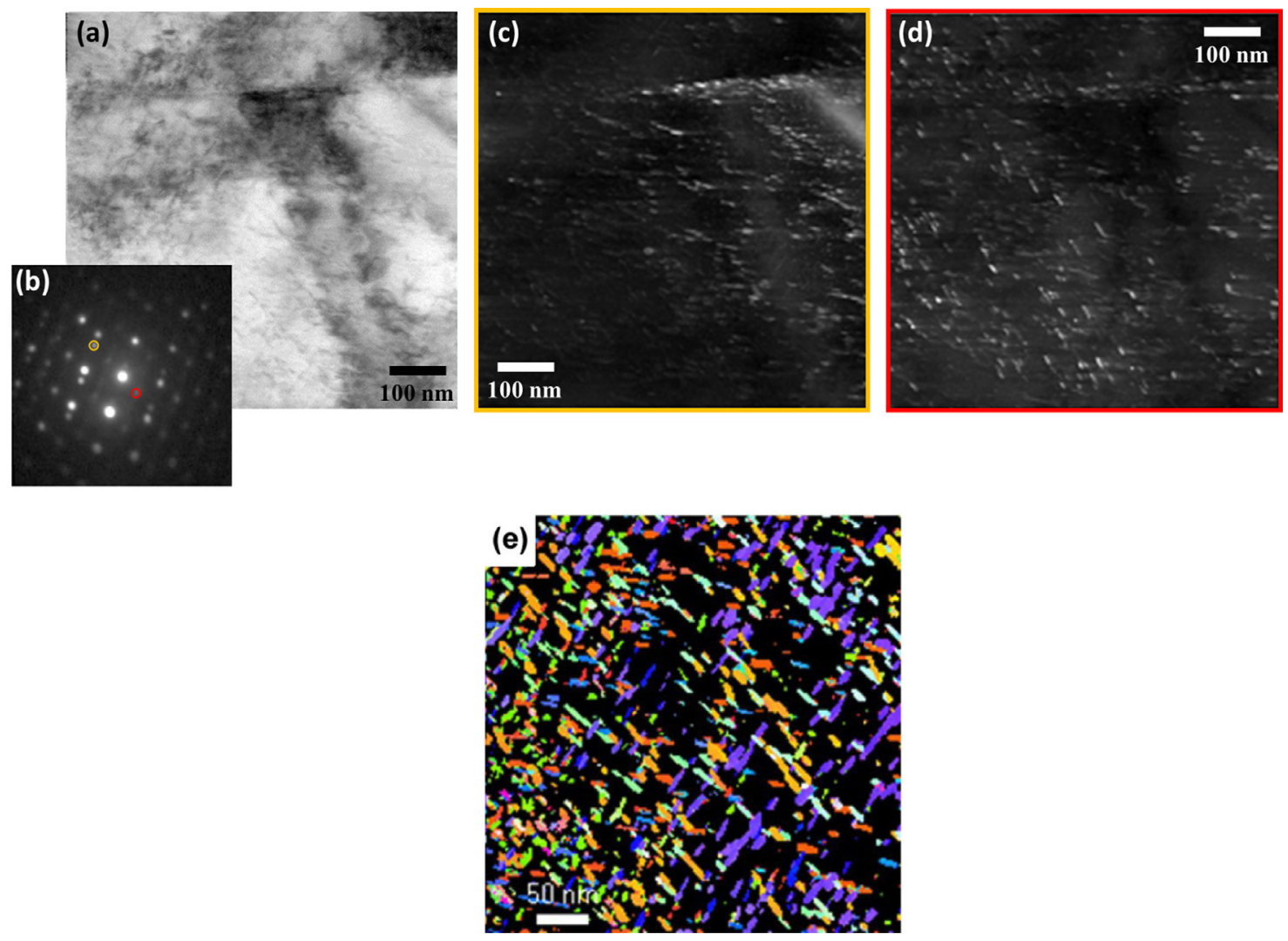

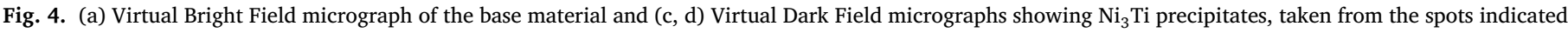
by the circles in the acquired diffraction pattern in one point in the image (b). (e) Reconstructed image of the different variants (see [55] for details).

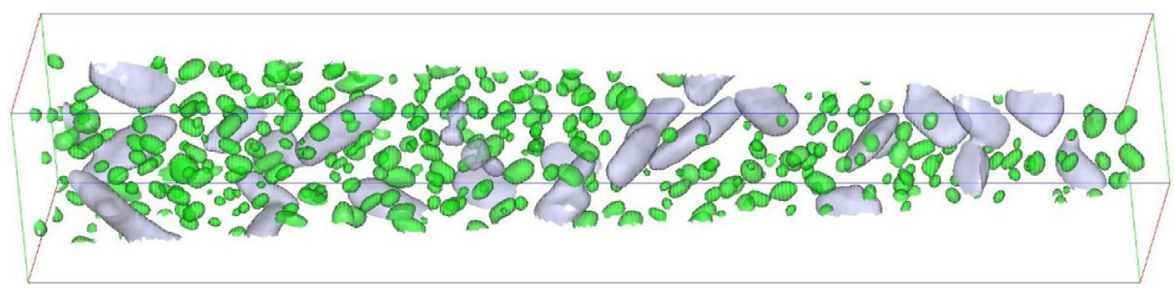

Fig. 5. Iso-surface of a reconstructed atom probe tip for a concentration in $\mathrm{Ni}$ of $30 \%$, with grey and green colour for the surfaces above and below $500 \mathrm{~nm}^{2}$. The reconstructed volume is $40 \times 40 \times 280 \mathrm{~nm}^{3}$

tained by Ifergane et al. [45] on the Custom 465 alloy or Munn and Anderson [54] on the PH13-8Mo alloy, both in aged condition.

\subsection{Fine-scale microstructure}

\subsubsection{Transmission Electron Microscopy}

Transmission electron microscopy of the aged specimen shows a martensitic structure containing a high density of dislocations (Virtual Bright-field (VBF) image in Fig. 4(a)). Virtual dark-field (VDF) images constructed from precipitate diffraction spots [48] are shown in Fig. 4(c) and (d). They reveal the presence of fine needle-like precipitates corresponding to the hexagonal $\eta-\mathrm{Ni}_{3} \mathrm{Ti}$ phase. The observed precipitates have average dimensions of $5 \mathrm{~nm} \times 14 \mathrm{~nm}$, which is in good agreement with the results obtained by Ifergane et al. [45], also on an aged C465 alloy. Using a multi-phase indexing strategy [55] for the phase identification implemented in the ACOM analysis software, the distribution of the different variants of the $\eta$ phase can be reconstructed, as shown in Fig. 4 (e), and the precipitate pole figures (see [55]) can be compared to that of the matrix. These pole figures confirm the reported orientation relationship between the $\eta$ phase and the matrix:

$$
\{1 \overline{1} 1\}_{\alpha \prime} / /\{11 \overline{2} 0\}_{\eta} \text { et }\{011\}_{\alpha \prime} / /\{0001\}_{\eta}
$$

\subsubsection{Atom Probe Tomography}

The initial precipitate microstructure has been further investigated by atom probe tomography. Fig. A1 in appendix shows the distribution of $\mathrm{Fe}, \mathrm{Cr}, \mathrm{Ni}$ and $\mathrm{Ti}$ atoms in a reconstructed volume. $\mathrm{Ni}$ and $\mathrm{Ti}$ rich precipitates are clearly evidenced. These precipitates are split into two morphologies, one corresponding to the rod morphology of the $\mathrm{Ni}_{3} \mathrm{Ti}$ phase observed by TEM (Fig. 4), and the other spheroidal, of much smaller size. These precipitates are both rich in Ni and Ti. Their distribution and morphology can be better visualized by representing the surface of iso-concentration (or iso-surface, for short) at a Ni concentration of $30 \%$ threshold, with a different colour for the particles whose surface are larger or smaller than $500 \mathrm{~nm}^{2}$. This representation is shown in Fig. 5. The precipitate distribution appears clearly bi-modal.

The composition of both precipitate families can be evaluated by calculating a proxigram for each of the two families (small and large particles). The two proxigrams, averaged on all precipitates of the same family in the reconstructed volume, are plotted in Fig. 6. A composition plateau is reached in both cases at the core of the precipitates, which indicates that the core composition should be a reliable measurement of the precipitate composition. For the small particles, the precipitate composition was calculated from the average of the proxigram between 2 and $2.5 \mathrm{~nm}$. However, when examining the mass spectrum of the anal- 

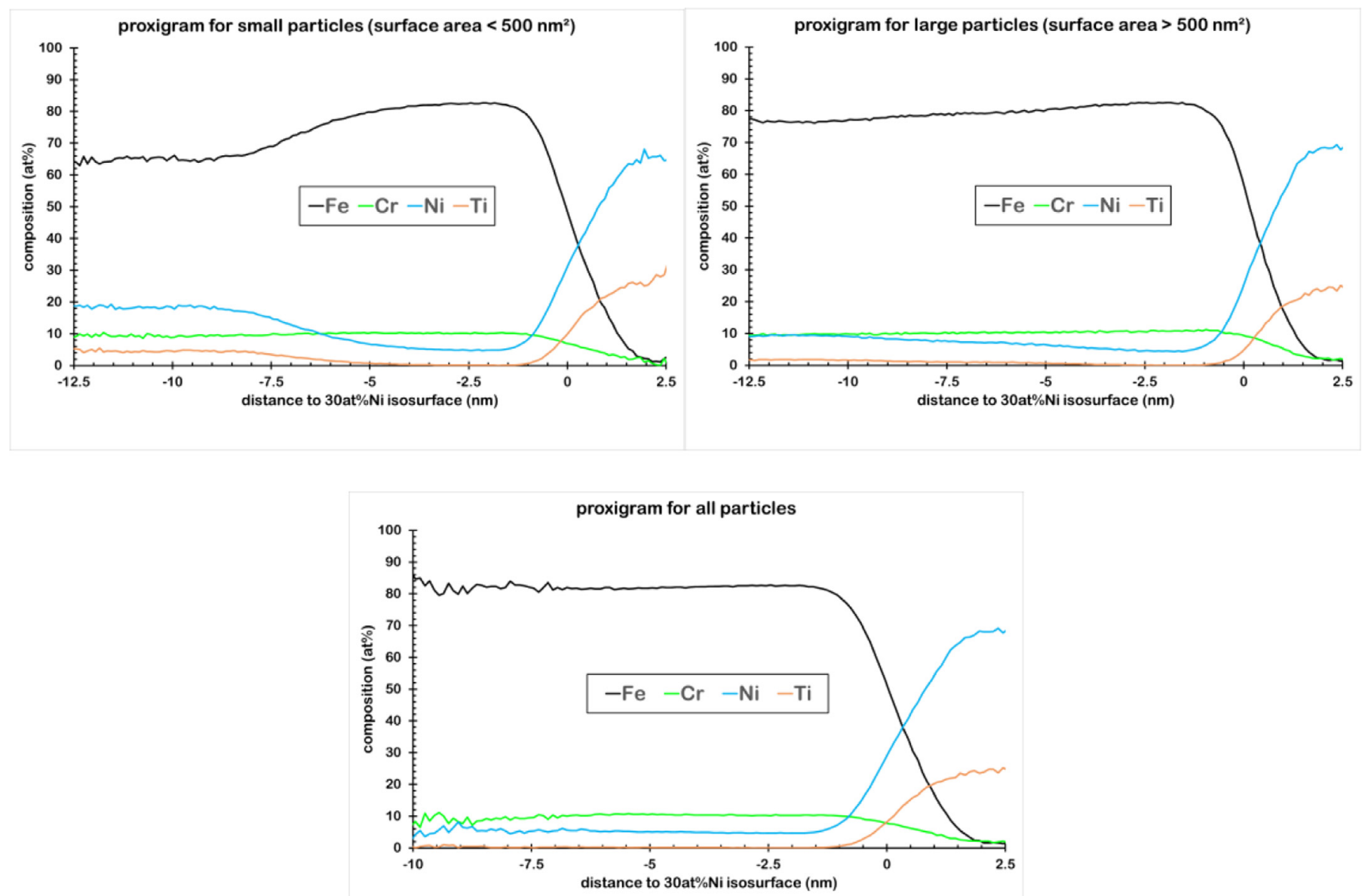

Fig. 6. Proxi-grams calculated on the $\mathrm{Ni}_{3}$ Ti particles as defined by the $30 \% \mathrm{Ni}$ iso-surface. Positive distances are within the particles and negative values are in the matrix. (a): proxi-gram on the small particles (as defined by the interface area); (b) proxigram on the large particles; (c) proxi-gram on all particles.

Table 2

Compositions (in at\%) obtained from the atom probe tomography analysis: nominal alloy content, overall composition of the atom probe tip, composition of the small and large particles, and composition of the matrix. Standard deviations (in brackets) are due to counting statistics.

\begin{tabular}{llllllll}
\hline & $\mathrm{Fe}$ & $\mathrm{Cr}$ & $\mathrm{Ni}$ & $\mathrm{Ti}$ & $\mathrm{Si}$ & $\mathrm{Mo}$ & $\mathrm{Al}$ \\
\hline Nominal & 73.8 & 12.3 & 10.5 & 1.97 & 1.0 & 0.52 & \\
Tip & $77.43(0.01)$ & $9.89(0.01)$ & $10.03(0.01)$ & $1.81(0.005)$ & $0.11(0.001)$ & $0.53(0.002)$ & $0.14(0.001)$ \\
Small & $2.24(0.03)$ & $0.21(0.01)$ & $67.10(0.08)$ & $28.07(0.08)$ & $1.37(0.02)$ & $0.26(0.01)$ & $0.28(0.01)$ \\
Large & $2.39(0.03)$ & $0.82(0.02)$ & $69.45(0.08)$ & $25.36(0.07)$ & $0.06(0.004)$ & $0.42(0.01)$ & $1.21(0.02)$ \\
Matrix & $83.67(0.01)$ & $10.55(0.01)$ & $5.00(0.01)$ & $0.12(0.001)$ & $0.07(0.001)$ & $0.51(0.003)$ & $0.04(0.001)$ \\
\hline
\end{tabular}

ysis, the overlap of the $52 \mathrm{Ti}$ and $52 \mathrm{Cr}$ isotopes results in an ambiguity of the measurement of these elements. By considering that the 52Ti isotope represents $5.18 \%$ of the total $\mathrm{Ti}$, a corrected composition was computed, given in Table 2. The same analysis was made on the large particles, and their corrected composition is also provided in Table 2 . These measurements show that the precipitate composition of both families is very similar, with a Ni content close to $2 / 3$, a Ti content close to $\frac{1}{4}$ and a very small residual $\mathrm{Fe}$ and $\mathrm{Cr}$ content ( $\sim 2$ and 1 at $\%$ respectively). The main compositional difference between the two precipitate families is their $\mathrm{Al}$ and $\mathrm{Si}$ contents: the small particles contain a much higher $\mathrm{Si}$ content (1.4 vs 0.1 at $\%$ ) whereas the large particles contain a higher $\mathrm{Al}$ content (1.2 vs. 0.3 at $\%)$.

The matrix concentration can also be determined by the proxigram method, provided that all particles, whatever their family, are considered simultaneously (Fig. 6c). A stable plateau is obtained, showing that there is no significant core-shell structure with solute elements expelled from the growing particles still present in high concentration around the particles. The matrix concentration is then calculated by averaging the plateau between -7.5 and $-2.5 \mathrm{~nm}$ and the resulting concentrations are provided in Table 2, along with the nominal alloy concentration and the overall composition of the atom probe tip. The solid solution appears to be almost free of residual $\mathrm{Ti}$ while the residual $\mathrm{Ni}$ concentration is still 5 at $\%$. Because of the low residual Ti amount, 52Ti correction was not applied to the matrix.

The number densities of the two precipitate families can be estimated from the number of objects detected in the atom probe tip. For the large particles, whose length is similar to the small dimensions of the reconstructed volume, each particle intercepted by the tip surface is counted as $\frac{1}{2}$ particle. The resulting precipitate number density of small and large particles, averaged on 5 measured samples, is respectively $5.10^{23}$ and $2.510^{22} \mathrm{~m}^{-3}$. Their respective volume fraction can be estimated by considering the number of atoms inside the iso-surfaces at $30 \% \mathrm{Ni}$, which 

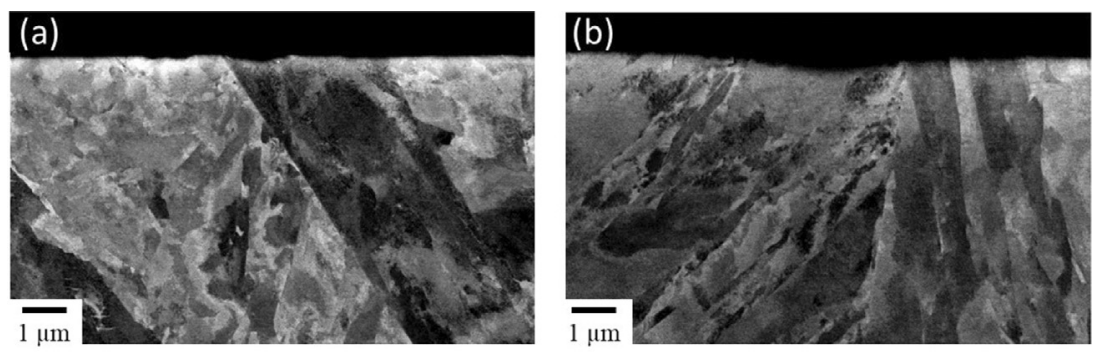

Fig. 7. Crystalline contrast SEM images of cross-sections of polished sample (a, b) and ground sample (c, d), respectively before (a, c) and after shot-peening (b, d).
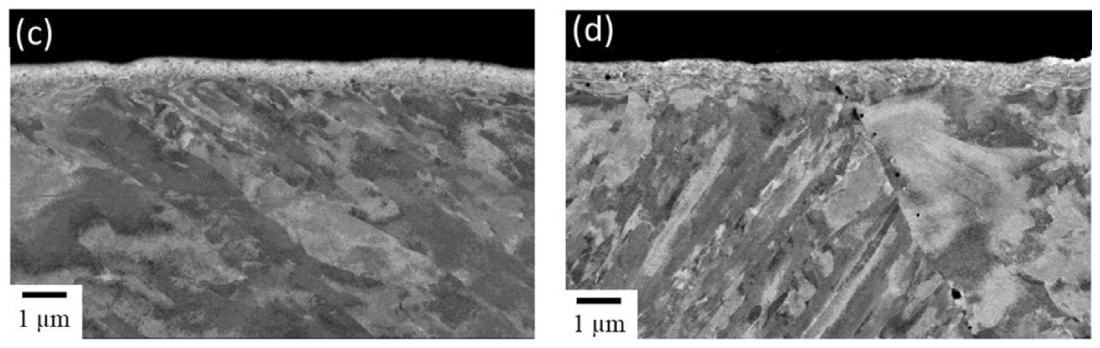

is for small and large particles respectively 329000 and 356000 atoms. This suggests that the volume fractions of the two precipitate families are approximately equal. The total volume fraction of the precipitates can be estimated by the solute balance between the precipitates and matrix, considering that the atomic volumes are identical in the precipitates and matrix. Using the $\mathrm{Ni}$ concentration, the solute balance provides a total precipitate volume fraction of $8.7 \%$ when calculated on the nominal alloy concentration, and $8.0 \%$ when calculated on the average tip concentration

\section{Effect of grinding and shot peening on the microstructure}

\subsection{Influence of grinding and shot peening on the microstructure at the grain scale}

A general view by crystalline contrast SEM of the microstructure of the sample cross-sections after machining and/or shot peening is given in Fig. 7. For the polished sample, there is no clear evidence of plastic deformation at the surface after shot peening, as the microstructure at this scale appears identical to that of the initial state. On the contrary, a layer of much finer microstructure is clearly observed close to the sample surface of the ground sample. This layer, which corresponds to the white layer reported in the literature, has an average thickness of about $1 \mu \mathrm{m}$. Chomienne et al. [56] report similar observations on the 15-5PH after turning, as well as Barry and Byrne [31] in two turned hardened martensitic steels. These SEM images show no significant modification of this layer after the shot-peening process. Thus, independently of the surface preparation applied (grinding or polishing), the grain structure does not seem to be affected by shot peening at this observation scale.

In order to characterize the extreme surface of the sample, in terms of morphological and structural features, grain size and phase transformations, observations using TEM-ACOM have been realized on FIBprepared cross-sections prepared at the sample surface. The virtual bright field images and the corresponding orientation and phase maps of the cross-sections of the polished samples before and after shot-peening are presented in Fig. 8. As expected, the polished sample does not show any surface particularity as compared to the bulk microstructure. The microstructure of the shot peened sample shows some sign of plastic deformation, with some near-surface diffraction contrast in the VBF image and moderate orientation gradients in the first $100 \mathrm{~nm}$ of depth. However, no major modification of the grain microstructure is observed in this state.
To provide a more precise view of the depth subjected to plastic deformation through the local distribution of mis-orientations, Kernel Average Mis-orientation (KAM) [57] analysis was performed. Fig. 9 presents the KAM maps generated from the orientation maps (scan size of $600 \times 600 \mathrm{~nm}^{2}$ ), considering the second neighbours and a threshold of $5^{\circ}$. This analysis indicates that shot peening results in some plastic deformation near the sample surface. New sub-grain boundaries (visible as green lines and corresponding to higher deformation within the grain) are observed.

The ACOM-TEM cross-sections corresponding to the ground sample before and after shot-peening are presented in Fig. 10. The direct surface of both samples exhibits a highly refined grain structure, compared to the bulk microstructure, whose thickness extends from 600 to $1200 \mathrm{~nm}$. The average grain size decreases gradually when approaching the sample surface. Crystallite size ranges are respectively for BCC and FCC phases (Figs. 10c, 10f) from 2 to $100 \mathrm{~nm}$ (average of $45 \mathrm{~nm}$ ) and from 2 to $35 \mathrm{~nm}$ (average of $15 \mathrm{~nm}$ ). Furthermore, observations reveal an increase of austenite content, with an average austenite surface fraction in this layer around $15 \%$. However, it must be pointed out that the austenite fraction observed in this near-surface region is relatively heterogeneous, as shown by the additional maps provided in appendix (fig. A2). Although it is always much larger than that of the base material, it is observed to vary significantly from place to place. Below this zone, larger grains presenting high orientation gradients are observed. No significant difference is observed between the microstructures of the ground specimens before and after shot-peening.

Analyses using GIXRD have been performed to complement this investigation and access the phase identification at near surface with a more macroscopic technique. An important point to be considered is that, since the characterization must be carried out in the immediate layer below the surface, no surface preparation can be carried out. Consequently, the surface shows significant roughness, and only a qualitative analysis of phase fractions can be conducted. For all experiments, an incident angle of $1.8^{\circ}$ has been used, which leads to a depth of penetration of X-Rays around $65 \mathrm{~nm}$. The GIXRD pattern corresponding to the four previous samples are presented in Fig. 11. The diffraction peaks of all samples correspond to BCC structure (marten site or ferrite) and FCC structure (austenite). By comparing GIXRD patterns of polished (a) or ground (c) samples, significant differences in austenite content are visible. The peaks corresponding to the austenite phase (FCC) are indeed much more intense for ground samples (c) than for polished sample (a). These results are in agreement with the previously shown TEM observations and confirm the large increase of austenite content at near sur- 
(a)

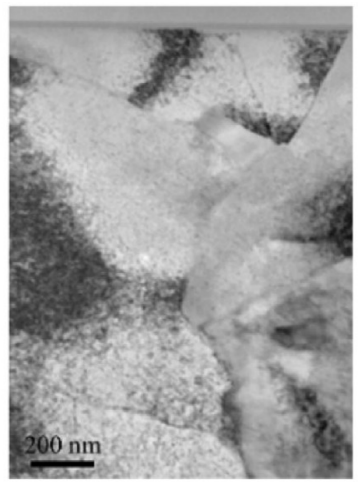

(d)

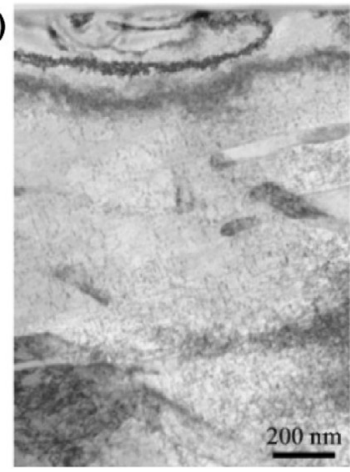

(b)

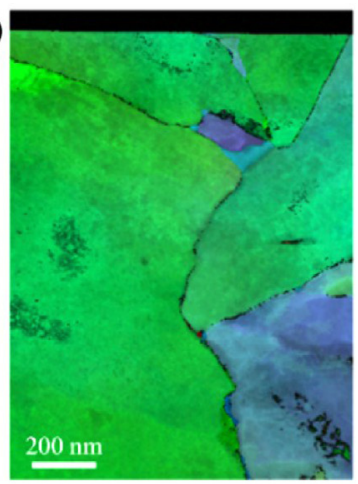

(e)

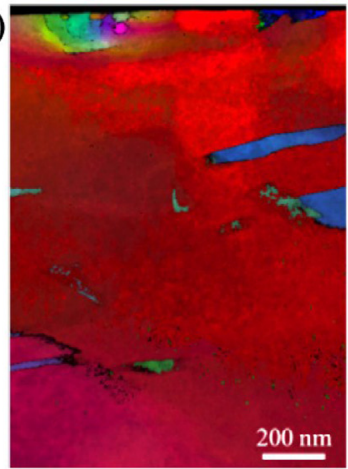

(c)

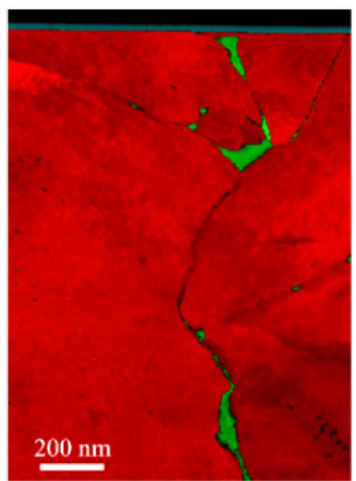

(f)

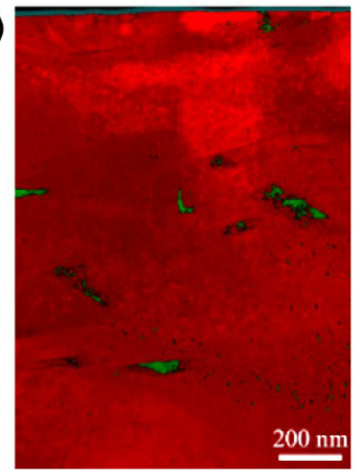

Fig. 8. Virtual bright field $(\mathrm{a}, \mathrm{d})$, orientation $(b, e)$ and phases maps $(c, f)$ of $(a, b, c)$ the polished sample and $(\mathrm{d}, \mathrm{e}, \mathrm{f})$ the polished and shotpeened sample obtained by ACOM-TEM experiments. For the orientation maps, BCC and FCC phases respectively appear in red and in green.
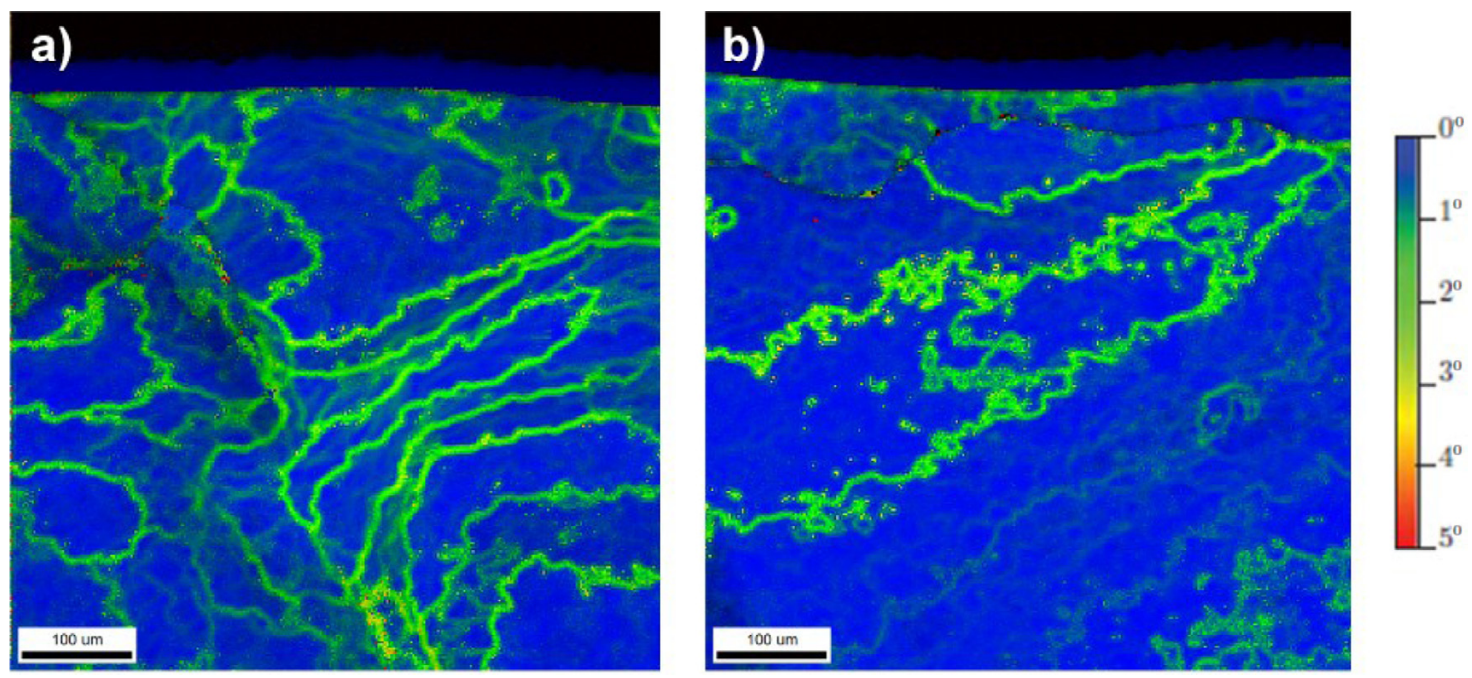

Fig. 9. KAM maps for near surface microstructure of polished samples (a) before and (b) after shot peening.

face due to the grinding process. Both patterns corresponding to ground samples before (c) and after shot peening (d) are quite similar, suggesting that shot peening has no noticeable effect on the near-surface austenite phase fraction. Even if quantitative analyses cannot be performed, the intensity of peaks corresponding to the austenite phase suggests that the austenite content formed during grinding is even higher than the proportion observed on TEM specimens. The lower austenite fraction observed in TEM specimens could result from the release of the residual stresses during TEM sample preparation which could trigger the transformation of some of the metastable austenite into marten site.
Additionally, the evolution of austenite volume fraction with the distance from the sample surface has been evaluated by XRD measurements. The procedure to obtain a depth profile of phase fractions was to perform successive diffraction measurements (with a penetration depth of X-rays estimated to $\sim 10 \mu \mathrm{m}$ using a Co X-ray source) followed by controlled polishing to a depth determined from the evolution of the shape of Vickers indents made prior to the measurements. Analyses have been carried out from a depth of $10 \mu \mathrm{m}$ from the surface until a depth of $1000 \mu \mathrm{m}$. The measurements of austenite content for the different samples are shown in Fig. 12. The samples not subjected to shot peening, i.e. after grinding or polishing only, show no significant 
(a)

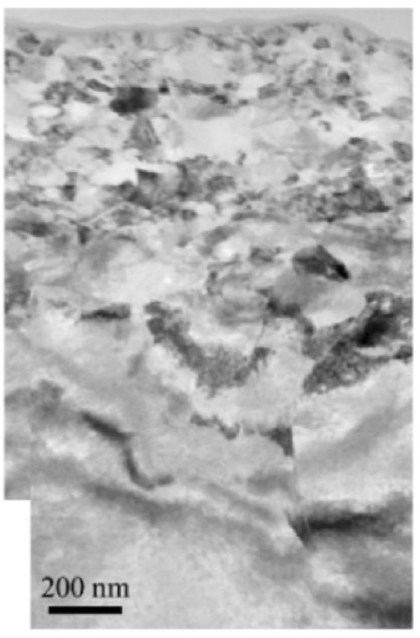

(d)

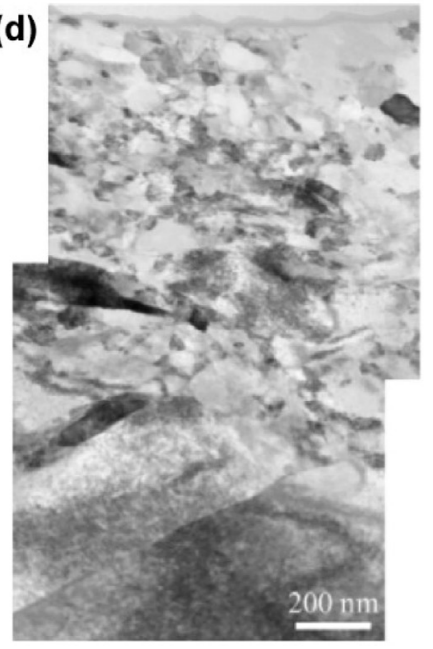

(b)

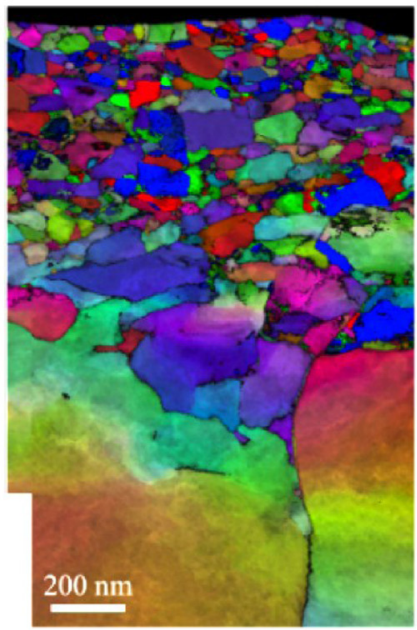

(e)

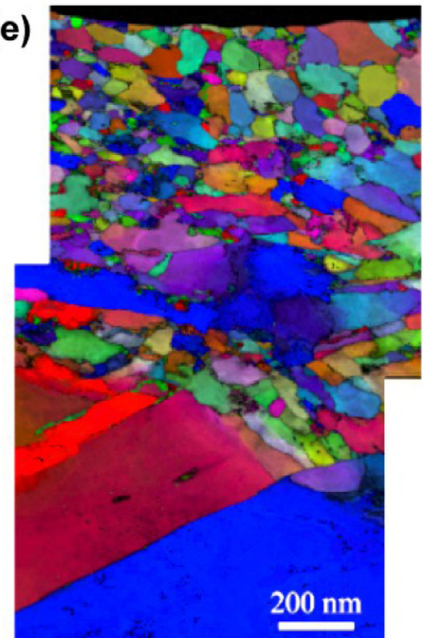

(c)

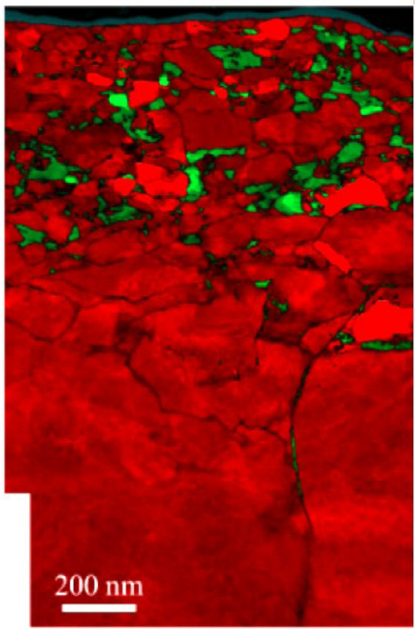

(f)

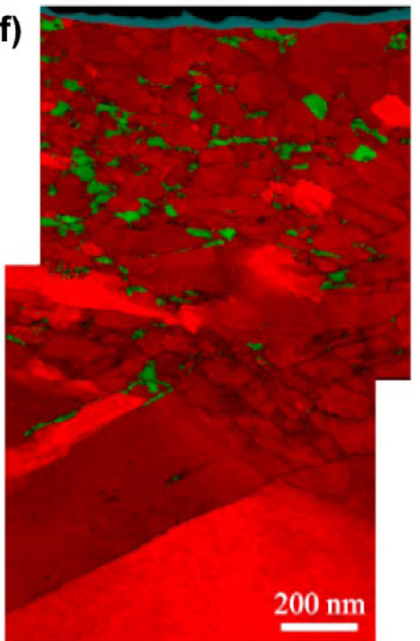

Fig. 10. Virtual bright field, orientation and phases maps of the ground sample (a, b, c) before and (d, e, f) after shot-peening obtained by ACOM-TEM experiments. For the orientation maps, BCC and FCC phases respectively appear in red and in green.

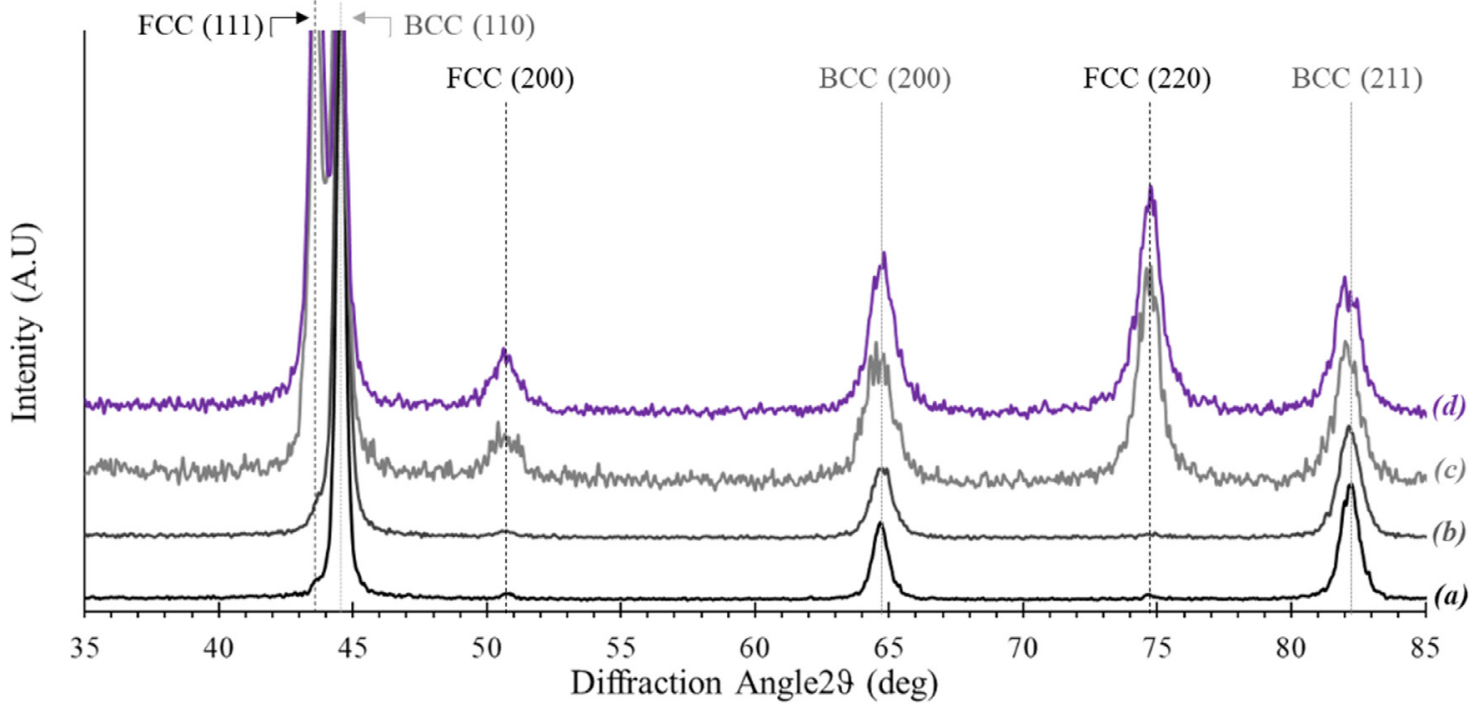

Fig. 11. GIXRD patterns of the (a) polished, (b) polished + shot peened, (c) ground and (d) ground + shot peened samples. 


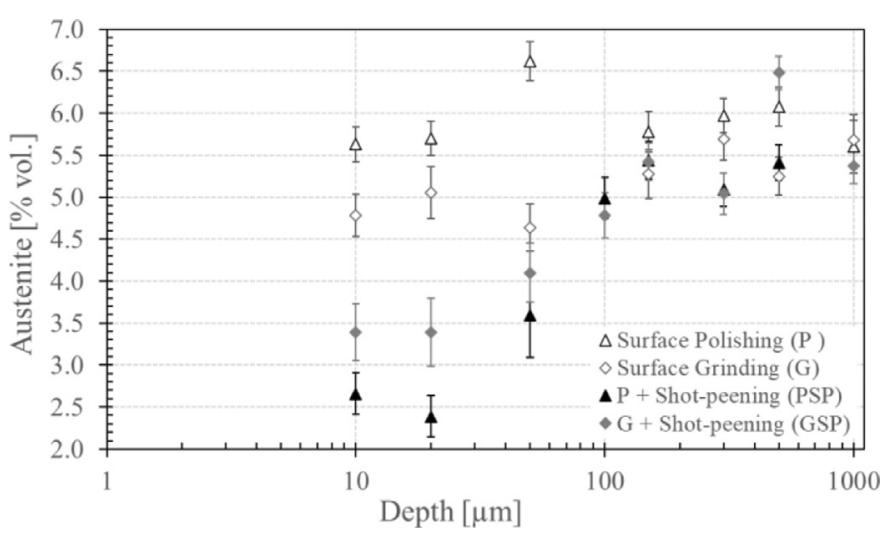

Fig. 12. Austenite volume fraction as a function of depth in reference material, grinding or in shot peened near surface regions of C465.

variation of the austenite fraction with depth. The average austenite volume fraction, determined from XRD patterns, is respectively of 5.8 and $5.2 \%$ for polished or ground samples (as compared to $5.8 \%$ for the bulk sample, see section 3.1). After shot peening, both samples show a decrease of the austenite content, which happens progressively over the first $100 \mu \mathrm{m}$ below the surface. Thus, shot peening results in the transformation of austenite to marten site near the surface, which reveals the mechanical instability of austenitic phase, as also observed by Kim et al. [25] for carburized SAE 4028, or Wong et al. [30] for the 17-4PH steel.

\subsection{Influence of grinding and shot peening on the precipitate microstructure}

Fig. 13 shows a TEM characterization of the rod-shaped $\eta$ precipitates near the sample surface in the polished + shot peened sample. The precipitate distribution remains homogeneous, comparable to the initial microstructure shown in Fig. 4. No modification of the precipitate microstructure caused by shot peening is visible.

Characterization of the machined state in the near surface is more difficult because of the extremely small grain size. Actually, it was not possible to reach a characterization using ACOM imaging, because the superposition of several grains in the TEM sample thickness prevented isolation of the weak precipitate diffraction spots. Thus, an APT characterization was carried out on the machined + shot peened specimen. The sample was prepared using a platinum coating to serve as surface protection. It is estimated that the apex of the sample whose reconstruction is shown in Fig. 14 is located within $100 \mathrm{~nm}$ from the surface. The APT characterization shows an almost homogeneous distribution of the main addition elements, especially $\mathrm{Ni}$ and Ti. This result thus strongly suggests that the $\eta$ precipitates are dissolved in the surface layer during

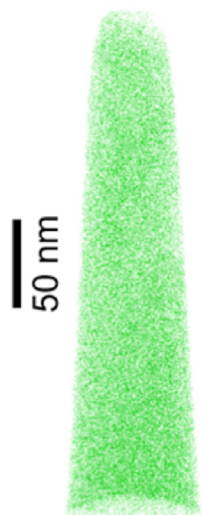

$\mathrm{Fe}$

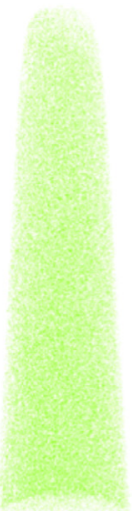

$\mathrm{Cr}$

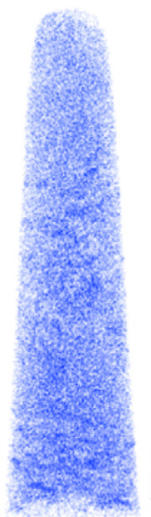

$\mathrm{Ni}$

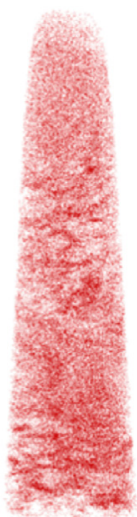

$\mathrm{Ti}$
Fig. 14. Atom probe tip at near surface of the machined + shot peened sample showing the distribution of $\mathrm{Fe}, \mathrm{Cr}, \mathrm{Nu}$ and $\mathrm{Ti}$ atoms.

the machining operation. Part of the APT specimen shows some degree of heterogeneity of the distribution of $\mathrm{Ti}$ and to a smaller degree of $\mathrm{Ni}$, which however cannot be attributed to well-defined $\eta$ precipitates. It could be the sign of remaining solute heterogeneity due to the precipitates dissolution.

\section{Discussion}

The present study aimed at reaching a detailed description of the microstructural modifications caused by grinding and shot peening processes on the aged C465 stainless steel. In order to compare the microstructural changes, a detailed analysis of the initial microstructure was first carried out, then the measurements and analyses were performed at near surface after grinding, after shot peening and after the combination of the two processes.

First, it is of interest to discuss the microstructure in the initial state. Overall, the microstructure corresponds to that found in the literature, with a hierarchical grain structure resulting from the aged marten site, and an austenite phase fraction slightly above $5 \%$. The high resolution of our ACOM-TEM measurements allow to precisely determine the shape and location of the austenite phase with respect to the marten site grains, namely at the grain and lath boundaries, similarly to what has been shown in other maraging stainless steels before [58]. At the microscopic scale, the presence of rod-shaped $\eta$ - $\mathrm{Ni}_{3} \mathrm{Ti}$ precipitates corresponds to the abundant literature on steels strengthened by $\mathrm{Ni}$ and $\mathrm{Ti}$ additions [43-46]. However, to our knowledge, the presence of small spherical precipitates observed in the present case has never been detected, although in retrospect it could be suspected in the TEM dark field micrographs of Ifergane et al. [45]. Even if we have no structural information on these spheroidal precipitates, the fact that their compo-

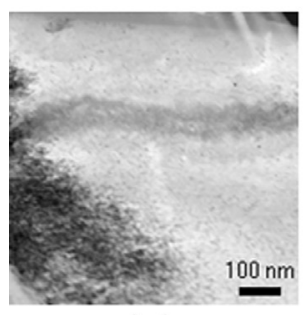

(a)

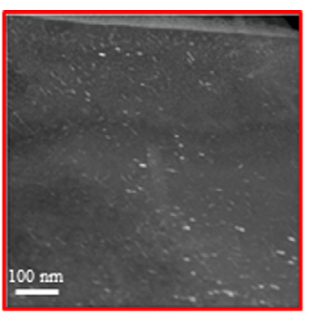

(b)

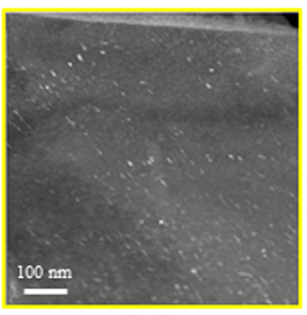

(c)

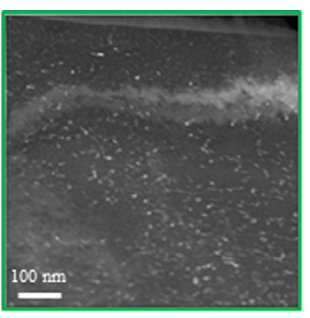

(d)

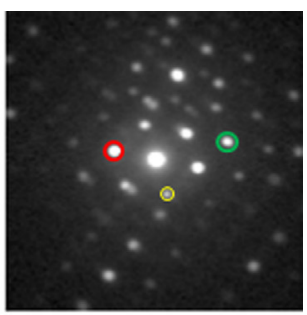

(e)

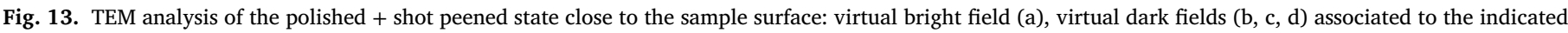
colour circles on the diffraction pattern (e). 
sition is almost identical to the rod-shaped ones strongly suggests that they are also of the $\eta-\mathrm{Ni}_{3} \mathrm{Ti}$ phase. It has been well established that the $\eta$ - $\mathrm{Ni}_{3} \mathrm{Ti}$ phase forms during ageing from the growth of spherical Ni and Ti rich clusters [46,59]. Besides, several studies have shown that the precipitation kinetics of $\eta$ - $\mathrm{Ni}_{3} \mathrm{Ti}$ is significantly accelerated by the presence of dislocations, e.g. by comparing materials subjected to different levels of strain $[59,60]$. Thus, a reasonable hypothesis for the presence of a bi-modal precipitate distribution is that the rod-shaped precipitates result from the growth of clusters nucleated at dislocations, while the spheroidal precipitates result from the growth of homogeneously nucleated clusters. Interestingly, while the alloying content in the major solute elements is almost the same in the two precipitate families $(\mathrm{Ni}$, Ti but also $\mathrm{Cr}, \mathrm{Fe}, \mathrm{Mo}$ ), relatively large differences exist in the (small) content of Si and $\mathrm{Al}$.

Now we can discuss the effect of grinding on the near surface of the material. Microstructural investigations have revealed the formation of an ultrafine structure in the surface layer of the machined material, similar to what is observed e.g. in the white and brown layers of pearlitic steels $[61,62]$ or during rolling contact fatigue [63]. The thickness of the affected layer is around $1 \mu \mathrm{m}$, which is consistent with the observations of Barbacki et al. [32]. This layer is composed of grains of extremely small size $(<100 \mathrm{~nm})$ corresponding to BCC and FCC phases. This result suggests that the white layer is in large part due to grain refinement induced by severe plastic deformation $[31,35]$. It was not possible to estimate precisely the austenite phase fraction in this layer. However, based on the TEM-ACOM observations, which probably underestimate the austenite phase fraction due to internal stress relaxation, and on the GIXRD measurements, this fraction lies in the $15-50 \%$ range, thus much higher than that of the base material. As it is highly unlikely that the deformation itself induces the formation of austenite, this high fraction indicates that the temperature reached in this zone during grinding is above the ferrite-to-austenite transus, with a ferrite-to-austenite transformation possibly accelerated by the deformation. It is at first sight surprising that this austenite does not transform into marten site upon cooling. This could be explained by two factors, namely the nanometre size of the grains, which retards the martensitic transformation [64], or a material transfer from the machining tool into this layer, such as carbon, which could stabilize the austenite phase. Due to a heterogeneous distribution of carbon in the measured atom probe tip it was very difficult to conclude on this last hypothesis, but overall the carbon content in the near surface was found higher than in the bulk material. The high temperature and very large strains reached in this nanostructured surface layer can also explain the complete disappearance of the precipitate microstructure in this zone as evidenced by APT, which results in an almost homogeneous distribution of solutes. Nano-indentation measurements have been carried out both in this surface layer and in the base material, and do not show any strong hardness variation as a function of the distance with the surface. This indicates that the absence of hardening precipitates is compensated in this zone by the presence of the grain nanostructure.

On the other hand, shot peening has a very different influence on the microstructure as compared to grinding. Our results show that the material deformation below the surface is relatively moderate. It is not sufficient to induce large changes in the grain structure, but results in intra-granular mis-orientations due to the presence of dislocations, both homogeneously distributed and organized in sub-grain boundaries. This visible effect of plastic deformation is much localized, in the first $\mu \mathrm{m}$ below the surface. At a much larger scale, our depth profile of the austenite phase fraction shows that shot peening results in a reduction of the austenite phase fraction by up to a factor of 2 down to $2.5 \%$. This reduction is strongest in the first $20 \mu \mathrm{m}$ but extends at least over $100 \mu \mathrm{m}$, thus at a much larger scale than the apparent plastic deformation. It corresponds to the generally reported austenite destabilization by strain or stress-induced phase transformation [64], however our results suggest that the stress effect is probably dominant. At precipitation level, no visible change in the precipitate size distribution is observed, consistently with the estimated very low plastic deformation and lack of strong temperature change. There does not seem to be any visible interaction between the grinding and shot peening processes: no change of the white layer due to grinding is observed after shot peening, and reversely the presence of the white layer does not seem to change the effect of shot peening on the austenite destabilization.

\section{Conclusion}

The effect of grinding and shot peening on the near-surface microstructure of Custom 465 have been analysed, based on the microstructure analysis of the main phases (marten site and austenite) and of the hardening precipitates $\left(\eta-\mathrm{Ni}_{3} \mathrm{Ti}\right)$. The comparative analysis of the different states makes it possible to evaluate the respective role of these two processes.

The initial microstructure consists of a classical martensitic structure with $\sim 5 \%$ retained austenite located at the grain and lath boundaries. The alloy is hardened by a dense distribution of $\eta-\mathrm{Ni}_{3} \mathrm{Ti}$, whose fraction is almost $10 \%$. Atom Probe Tomography reveals, for the first time to the authors' knowledge, that these precipitates have a bi-modal distribution, consisting of small spheroidal precipitates and the classical larger rodshape precipitates. It is suspected that these two families are respectively nucleated in the bulk and on the marten site's dislocations.

Grinding induces the formation of a white layer at the alloy's surface. ACOM-TEM analyses revealed that the grain sizes of the white layer were considerably smaller $(<100 \mathrm{~nm})$ than the bulk, as a result of the severe plastic deformation. This layer extends to approximately $500 \mathrm{~nm}$ below the sample surface. Furthermore, the austenite fraction in this layer is very high, in the range $15-50 \%$, accompanied by almost complete dissolution of the hardening $\eta-\mathrm{Ni}_{3} \mathrm{Ti}$ precipitates. These two features are compatible with a thermally-induced formation of austenite and precipitate dissolution, and a high fraction of retained austenite due to the nano crystalline grain size and possibly a carbon enrichment due to transfer from the cutting tool.

Shot peening results in the decrease of retained austenite content in a depth of about $100 \mu \mathrm{m}$, by a strain or stress-induced transformation of austenite. This effect does not seem to interact with the effect of grinding. This multi-scale complexity of sub-surface microstructure and associated mechanical behaviour will have to be considered when evaluating the material's mechanical behaviour.

\section{Declaration of Competing Interest}

The authors declare that they have no known competing financial interests or personal relationships that could have appeared to influence the work reported in this paper.

\section{Acknowledgements}

F. Robaut is thanked for help with EBSD observations. APT work was carried out owing to experimental GENESIS platform. GENESIS is supported by the Région Haute-Normandie, the Métropole Rouen Normandie, the CNRS via LABEX EMC, and the French National Research Agency as a part of the program "Investissements d'avenir" with the reference ANR-11-EQPX-0020. Fabien Cuvilly is thanked for the lift out work. The authors acknowledge financial support from the CNRSCEA "METSA" French network (FR CNRS 3507) on the GPM platform (Rouen). 


\section{Appendix}

Figs. A1 and A2

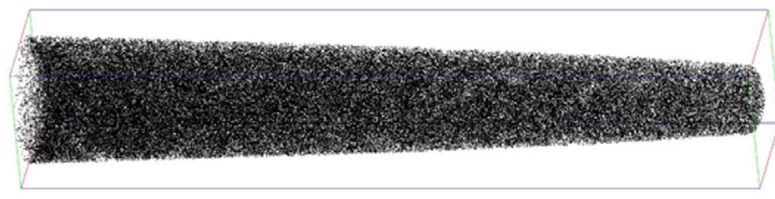

Fe ( $2 \%$ of the atoms)

$\mathrm{Ni}(10 \%$ of the atoms)

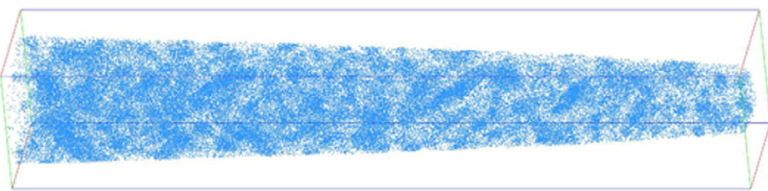

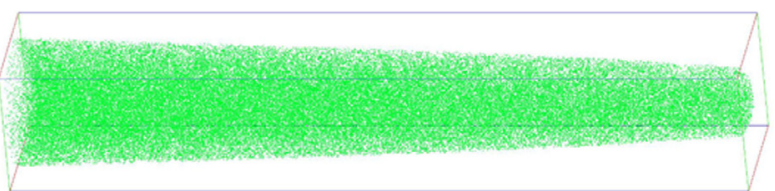

$\mathrm{Cr}(10 \%$ of the atoms)

$\mathrm{Ti}(100 \%$ of the atoms)

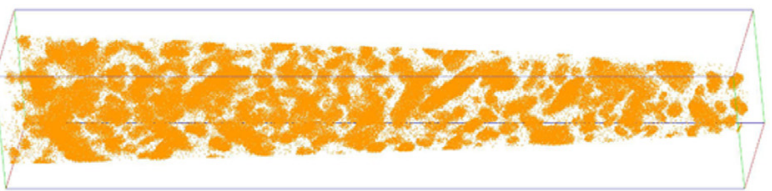

\section{Represented volume: $40 \times 40 \times 280 \mathrm{~nm}^{3}$}

Fig. A1. Distribution of the main solutes in an atom probe tip of the reference material (bulk of the aged alloy)
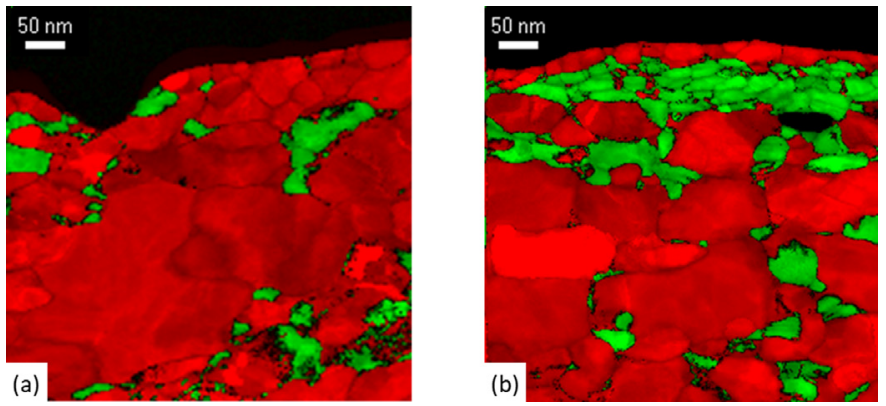

Fig. A2. Additional phase maps of the near-surface microstructure of the ground sample, showing in red the BCC phase and in green the FCC phase. These additional maps illustrate that the austenite fraction in the sub-surface region shows large local fluctuations.

\section{References}

[1] J. Davis, Alloy Digest Sourcebook: Stainless steels, ASM Intern, Materials Park, OH, 2000.

[2] W. Sha, Z. Guo, W. Sha, Z. Guo, Mechanical properties of maraging steels, Maraging Steels (2009) 49-66, doi:10.1533/9781845696931.49.

[3] B.T. Daymond, N. Binot, M.L. Schmidt, S. Preston, R. Collins, A. Shepherd, Development of custom $465 \AA$ corrosion-resisting steel for landing gear applications, J. Mater. Eng. Perform. 25 (2016) 1539-1553, doi:10.1007/s11665-015-1830-5.

[4] R.G. Bonora, H.J.C. Voorwald, M.O.H. Cioffi, Influence of shot peening on the fatigue strength of custom 465 stainless steel for aeronautic application, Adv. Mater. Res. 891-892 (2014) 668-673, doi:10.4028/www.scientific.net/AMR.891-892.668.

[5] N. Kawagoishi, T. Nagano, M. Moriyama, E. Kondo, Improvement of fatigue strength of maraging steel by shot peening, Mater. Manuf. Process. 24 (2009) 1431-1435, doi:10.1080/10426910903386055.

[6] M. Moriyama, T. Nagano, N. Kawagoishi, S. Takaki, E. Nagashima, Effects of shot peening on fatigue strength of $18 \% \mathrm{Ni}$ maraging steel, JSME Int. J. Ser. A. 44 (2001) 301-308 doi.org/10.1299/jsmea.44.301.

[7] Y.-K. Gao, Y.-F. Yin, M. Yao, Effects of shot peening on fatigue properties of $0 \mathrm{Cr} 13 \mathrm{Ni8Mo} 2 \mathrm{Al}$ steel effects of shot peening on fatigue properties of 0Cr1 3Ni8Mo2Al steel, Mater. Sci. Technol. 19 (2003) 372-374, doi:10.1179/026708303225010650.

[8] M.A.S. Torres, H.J.C. Voorwald, An evaluation of shot peening, residual stress and stress relaxation on the fatigue life of AISI 4340 steel, Int. J. Fatigue. 24 (2002) 877-886, doi:10.1016/S0142-1123(01)00205-5.

[9] Y.K. Gao, M. Yao, P.G. Shao, Y.H. Zhao, Another mechanism for fatigue strength improvement of metallic parts by shot peening, J. Mater. Eng. Perform. 12 (2003) 507-511, doi:10.1361/105994903100277148.
[10] S. Bagherifard, R. Ghelichi, M. Guagliano, Numerical and experimental analysis of surface roughness generated by shot peening, Appl. Surf. Sci. 258 (2012) 6831-6840, doi:10.1016/j.apsusc.2012.03.111.

[11] R. Clausen, J. Stangenberg, Roughness of shot-peened surfaces - definition and measurement, in: Proc. 7th Int. Conf. Shot Peen. ICSP7, Warsaw, Poland, 1999, pp. 69-77.

[12] G.H. Farrahi, J.L. Lebrijn, D. Couratin, Effect of shot peening on residual stress and fatigue life of a spring steel, Fatigue Fract. Eng. Mater. Struct. 18 (1995) 211-220, doi:10.1111/j.1460-2695.1995.tb00156.x.

[13] M. Kobayashi, T. Matsui, Y. Murakami, Mechanism of creation of compressive residual stress by shot peening, Int. J. Fatigue. 20 (1998) 351-357, doi:10.1016/S0142-1123(98)00002-4.

[14] V. Schulze, Characteristics of surface layers produced by shot peening, in: Proc. 8th Int. Conf. Shot Peen. ICSP 8, Garmisch-Partenkirchen DGM, 2002, pp. 145-160.

[15] V. Llaneza, F.J. Belzunce, Study of the effects produced by shot peening on the surface of quenched and tempered steels: roughness, residual stresses and work hardening, Appl. Surf. Sci. 356 (2015) 475-485, doi:10.1016/j.apsusc.2015.08.110.

[16] S. Bagherifard, M. Guagliano, Fatigue behavior of a low-alloy steel with nanostructured surface obtained by severe shot peening, Eng. Fract. Mech. 81 (2012) 56-68, doi:10.1016/j.engfracmech.2011.06.011.

[17] T. Wang, J. Yu, B. Dong, Surface nano-crystallization induced by shot peening and its effect on corrosion resistance of $1 \mathrm{Cr} 18 \mathrm{Ni}$ Ti stainless steel, Surf. Coat. Technol. 200 (2006) 4777-4781, doi:10.1016/j.surfcoat.2005.04.046.

[18] G. Liu, S.C. Wang, X.F. Lou, J. Lu, K. Lu, Low carbon steel with nanostructured surface layer induced by high-energy shot peening, Scr. Mater. 44 (2001) 17911795, doi:10.1109/SSST.2007.352347.

[19] O. Unal, R. Varol, Almen intensity effect on microstructure and mechanical properties of low carbon steel subjected to severe shot peening, Appl. Surf. Sci. 290 (2014) 40-47, doi:10.1016/j.apsusc.2013.10.184.

[20] Y. Todaka, M. Umemoto, K. Tsuchiya, Comparison of nano-crystalline surface layer in steels formed by air blast and ultrasonic shot peening, Mater. Trans. 45 (2004) 376-379, doi:10.2320/matertrans.45.376.

[21] T. Roland, D. Retraint, K. Lu, J. Lu, Fatigue life improvement through surface nanostructuring of stainless steel by means of surface mechanical attrition treatment, Scr. Mater. 54 (2006) 1949-1954, doi:10.1016/j.apsusc.2017.07.181.

[22] D. Li, H.N. Chen, H. Xu, The effect of nanostructured surface layer on the fatigue behaviors of a carbon steel, Appl. Surf. Sci. 255 (2009) 3811-3816, doi:10.1016/j.apsusc.2008.10.037.

[23] N.R. Tao, Z.B. Wang, W.P. Tong, M.L. Sui, J. Lu, K. Lu, An investigation of surface nano-crystallization mechanism in Fe induced by surface mechanical attrition treatment, Acta Mater 50 (2002) 4603-4616, doi:10.1016/S1359-6454(02)00310-5.

[24] E. Maleki, O. Unal, Roles of surface coverage increase and re-peening on properties of AISI 1045 carbon steel in conventional and severe shot peening processes, Surf. Interfaces. 11 (2018) 82-90, doi:10.1016/j.surfin.2018.03.003.

[25] C. Kim, D.E. Diesburg, R.M. Buck, Influence of sub-zero and shot-peening treatments on impact and fatigue fracture properties of case-hardened steels, J. Heat Treat. 2 (1981) 43-53 https://doi-org.gaelnomade-1.grenet.fr/10.1007/BF02833073.

[26] P. Fu, K. Zhan, C. Jiang, Micro-structure and surface layer properties of 18CrNiMo7-6 steel after multistep shot peening, Mater. Des. 51 (2013) 309-314, doi:10.1016/j.matdes.2013.04.011. 
[27] M. Chen, H. Liu, L. Wang, C. Wang, K. Zhu, Z. Xu, C. Jiang, V. Ji, Evaluation of the residual stress and microstructure character in SAF 2507 duplex stainless steel after multiple shot peening process, Surf. Coat. Technol. 344 (2018) 132-140, doi:10.1016/j.surfcoat.2018.03.012.

[28] D. Kirk, N.J. Payne, Transformations induced in austenitic stainless steels by shot peening, in: Proc. 7th Int. Conf. Shot Peen. ICSP7, Warsaw, Poland, 1999, pp. 15-22.

[29] G. Fargas, J.J. Roa, A. Mateo, Effect of shot peening on metastable austenitic stainless steels, Mater. Sci. Eng. A. 641 (2015) 290-296, doi:10.1016/j.msea.2015.05.079.

[30] Z. Wang, C. Jiang, X. Gan, Y. Chen, Effect of shot peening on the microstructure of laser hardened 17-4PH, Appl. Surf. Sci. 257 (2010) 1154-1160, doi:10.1016/j.apsusc.2010.07.015.

[31] J. Barry, G. Byrne, TEM study on the surface white layer in two turned hardened steels, Mater. Sci. Eng. A. 325 (2002) 356-364, doi:10.1016/S0921-5093(01)01447-2.

[32] A. Barbacki, M. Kawalec, A. Hamrol, Turning and grinding as a source of microstructural changes in the surface layer of hardened steel, J. Mater. Process. Technol. 133 (2003) 21-25, doi:10.1016/S0924-0136(02)00211-X.

[33] S. Akcan, W.I.S. Shah, S.P. Moylan, P.N. Chhabra, S. Chandrasekar, H.T.Y. Yang, Formation of white layers in steels by machining and their characteristics, Metall. Mater. Trans. A. 33 (2002) 1245-1254, doi:10.1007/s11661-002-0225-z.

[34] V. Bedekar, R. Shivpuri, R. Chaudhari, R.S. Hyde, Nano structural evolution of hard turning layers in response to insert geometry, cutting parameters and material microstructure, CIRP Ann. - Manuf. Technol. 62 (2013) 63-66, doi:10.1016/j.cirp. 2013.03.090.

[35] A. Ramesh, S.N. Melkote, L.F. Allard, L. Riester, T.R. Watkins, Analysis of white layers formed in hard turning of AISI 52100 steel, Mater. Sci. Eng. A. 390 (2005) 88-97, doi:10.1016/j.msea.2004.08.052.

[36] D.M. Turley, The nature of the white-etching surface layers produced during reaming ultra-high strength steel, Mater. Sci. Eng. 19 (1975) 79-86, doi:10.1016/0025-5416(75)90010-5.

[37] J. Jaworski, T. Trzepieciński, Surface layer properties of low-alloy highspeed steel after grinding, Acta Mech. Autom. 10 (2016) 275-279, doi:10.1515/ama-2016-0042.

[38] Y.K. Chou, C.J. Evans, White layers and thermal modeling of hard turned surfaces, Int. J. Mach. Tools Manuf. 39 (1999) 1863-1881, doi:10.1016/S0890-6955(99)00036-X.

[39] S.B. Hosseini, K. Ryttberg, J. Kaminski, U. Klement, Characterization of the surface integrity induced by hard turning of bainitic and martensitic AISI 52100 steel, Procedia CIRP 1 (2012) 494-499, doi:10.1016/j.procir.2012.04.088.

[40] V.M. Kardonskii, M.D. Perkas, Aging of Marten site in Fe- Ni- Mn steels, Metalloved. Termicheskaya Obrab. Met. (1966) 7-10.

[41] V.K. Vasudevan, S.J. Kim, C.M. Wayman, Precipitation Reactions and Strengthening Behavior in 18 Wt Pct Nickel Maraging Steels, Metall. Trans. A. 21 (1990) 2655-2668.

[42] J.I.N.I. Suk, S.H. Hong, S.O.W. Nam, Crystallographic orientation relationships among -Ni3Ti Precipitate, Reverted Austenite, and Martensitic Matrix in Fe-IOCr-IONi-2W Maraging Alloy, Metall. Trans. A. 24 (1993) 2643-2652.

[43] O. Moshka, M. Pinkas, E. Brosh, V. Ezersky, L. Meshi, Addressing the issue of precipitates in maraging steels - unambiguous answer, Mater. Sci. Eng. -Struct. Mater. Prop. Microstruct. Process. 638 (2015) 232-239, doi:10.1016/j.msea.2015.04.067.

[44] E.I. Galindo-Nava, W.M. Rainforth, P.E.J. Rivera-Diaz-del-Castillo, Predicting microstructure and strength of maraging steels: elemental optimization, Acta Mater 117 (2016) 270-285, doi:10.1016/j.actamat.2016.07.020.

[45] S. Ifergane, M. Pinkas, Z. Barkay, E. Brosh, V. Ezersky, O. Beeri, N. Eliaz, The relation between aging temperature, microstructure evolution and hardening of Custom 465® stainless steel, Mater. Charact. 127 (2017) 129-136, doi:10.1016/j.matchar.2017.02.023.
[46] M. Niu, G. Zhou, W. Wang, M.B. Shahzad, Y. Shan, K. Yang, Precipitate evolution and strengthening behavior during aging process in a $2.5 \mathrm{GPa}$ grade maraging steel, Acta Mater. 179 (2019) 296-307, doi:10.1016/j.actamat.2019.08.042

[47] E.F. Rauch, M. Veron, Coupled microstructural observations and local texture measurements with an automated crystallographic orientation mapping tool attached to a tem, Mater. Werkst. 36 (2005) 552-556, doi:10.1002/mawe.200500923.

[48] E.F. Rauch, M. Véron, Automated crystal orientation and phase mapping in TEM, Mater. Charact. 98 (2014) 1-9, doi:10.1016/j.matchar.2014.08.010.

[49] B. Gault, M.P. Moody, J.M. Cairney, S.P. Ringer, Atom Probe Microscopy, SpringerVerlag, New York, 2012, doi:10.1007/978-1-4614-3436-8.

[50] S. Morito, S. Yoshida, R. Hayamizu, T. Hayashi, T. Ohba, H. Terasaki, Y.I. Komizo, Three-dimensional approach to observing growth of blocks and packets in Fe-18Ni maraging steel, Mater. Sci. Forum. 783-786 (2014) 916-919, doi:10.4028/www.scientific.net/MSF.783-786.916.

[51] I. Tamura, K. Tzuzaki, T. Maki, Morphology of lath marten site formed from deformed austenite in 18\% Ni maraging steel, J. Phys. Colloq. 43 (1982) 551-556, doi:10.1051/jphyscol:1982486.

[52] S. Morito, H. Tanaka, R. Konishi, T. Furuhara, T. Maki, The morphology and crystallography of lath marten site in Fe-C alloys, Acta Mater 51 (2003) 1789-1799, doi:10.1016/S1359-6454(02)00577-3.

[53] H. Kitahara, R. Ueji, N. Tsuji, Y. Minamino, Crystallographic features of lath marten site in low-carbon steel, Acta Mater 54 (2006) 1279-1288, doi:10.1016/j.actamat.2005.11.001.

[54] P. Munn, B. Andersson, Hydrogen embrittlement of PH13-8Mo steel in simulated real-life tests and slow strain rate tests, Corrosion 46 (1990) 286-295, doi:10.5006/1.3585104.

[55] E.F. Rauch, M. Veron, Methods for orientation and phase identification of nano-sized embedded secondary phase particles by 4D scanning precession electron diffraction, Acta Crystallogr. Sect. B-Struct. Sci. Cryst. Eng. Mater. 75 (2019) 505-511, doi: $10.1107 /$ S2052520619007583.

[56] V. Chomienne, F. Valiorgue, J. Rech, C. Verdu, Influence of Part's stiffness on surface integrity induced by a finish turning operation of a 15-5PH Stainless Steel, Procedia CIRP 45 (2016) 19-22, doi:10.1016/j.procir.2016.02.331.

[57] S.I. Wright, M.M. Nowell, D.P. Field, Review of strain analysis using electron backscatter diffraction, Microsc. Microanal. 17 (2011) 316-329.

[58] L. Couturier, F. De Geuser, M. Descoins, A. Deschamps, Evolution of the microstructure of a 15-5PH martensitic stainless steel during precipitation hardening heat treatment, Mater. Des. 107 (2016) 416-425, doi:10.1016/j.matdes.2016.06.068.

[59] A. Shekhter, H.I. Aaronson, M.K. Miller, S.P. Ringer, E.V. Pereloma, Effect of aging and deformation on the microstructure and properties of Fe-Ni-Ti maraging steel, Metall. Mater. Trans. -Phys. Metall. Mater. Sci. 35A (2004) 973-983.

[60] Y. Lian, J. Huang, J. Zhang, C. Zhao, W. Gao, Z. Zhang, M. Ma, Effects of cold rolling on the microstructure and properties of Fe-Cr-Ni-Mo-Ti maraging steel, Mater. Sci. Eng. -Struct. Mater. Prop. Microstruct. Process. 712 (2018) 663-670, doi:10.1016/j.msea.2017.12.041.

[61] J. Takahashi, Y. Kobayashi, M. Ueda, T. Miyazaki, K. Kawakami, Nano-scale characterization of rolling contact wear surface of pearlitic steel, Mater. Sci. Technol. 29 (2013) 1212-1218, doi:10.1179/1743284713Y.0000000256

[62] A. Kumar, G. Agarwal, R. Petrov, S. Goto, J. Sietsma, M. Herbig, Microstructural evolution of white and brown etching layers in pearlitic rail steels, Acta Mater 171 (2019) 48-64, doi:10.1016/j.actamat.2019.04.012.

[63] H. Fu, P.E.J. Rivera-Díaz-del-Castillo, Evolution of white etching bands in $100 \mathrm{Cr} 6$ bearing steel under rolling contact-fatigue, Metals 9 (2019) 491, doi:10.3390/met9050491.

[64] A. Mandal, S. Morankar, M. Sen, S. Samanta, S.B. Singh, D. Chakrabarti, A descriptive model on the grain size dependence of deformation and martensitic transformation in austenitic stainless steel, Metall. Mater. Trans. -Phys. Metall. Mater. Sci. 51 (2020) 3886-3905, doi:10.1007/s11661-020-05861-7. 